\title{
Red Cell Metabolic Alterations in Postnatal Life in Term Infants: Glycolytic Intermediates and Adenosine Triphosphate
}

\author{
SUSAN F. TRAVIS, ${ }^{(22)}$ SAVITRI P. KUMAR, AND MARIA DELIVORIA-PAPADOPOULOS \\ Department of Pediatrics and Cardeza Foundation for Hematologic Research. Thomas Jefferson University School of \\ Medicine and Departments of Pediatrics and Physiology, University of Pennsylvania School of Medicine; Philadelphia,
} Pennsylvania, USA

\begin{abstract}
Summary
Red cell glycolytic intermediates and adenosine triphosphate were evaluated in term infants from birth to one year of age and compared to values obtained from normal adults and subjects with a population of a similar mean cell age. The concentration of glycolytic intermediates, with the exception of phosphoenolpyruvate were elevated at birth when compared to normal subjects, consistent with a young mean red cell population. The mean levels of red cell glucose-6-phosphate, fructose-6-phosphate, and "total triose phosphate" were elevated on days 1 and 4 of life when compared to both red cells from normal adults and subjects with a similar young mean red cell age. Glucose-6-phosphate steadily increased in concentration, peaked at 3 to $4 \mathrm{wk}$ of age, and then progressively decreased in value. Total triose phosphate declined to a mildly elevated concentration by 3 to 4 wk of age. The mean concentrations of 2,3-diphosphoglycerate and adenosine triphosphate were normal on day 1 , increased on day 4 , and then declined by 3 to 4 wk to normal values, until 5 to 6 months when both increased. The mean phosphoenolpyruvate concentration was decreased on day 1 of age when compared to red cells of a similar mean age, but this decrease was not significant $(P>0.05)$.

The mean concentrations of 3-phosphoglycerate and 2-phosphoglycerate were normal for mean red cell age on day 1 of life. The concentration of 2-phosphoglycerate increased at 3 to 4 wk of age and remained elevated for cell age at 11 to 12 months but this increase was not statistically significant $(P>0.05)$. 3-Phosphoglycerate levels did not change significantly throughout the first year of life. At one year of age, all red cell glycolytic intermediates and adenosine triphosphate were elevated when compared to red cells from normal adults, but were comparable to those observed in subjects with a red cell population of a similar mean cell age, consistent with the persistence of a young red cell population throughout the first year of life.
\end{abstract}

\section{Speculation}

The pattern of glycolytic intermediates in the first year of life is suggestive of a relative "block" in glycolysis at the phosphofructokinase step. This block appears to result from factors other than decreased enzyme activity alone and may be secondary to an enzyme with altered kinetic properties and/or the influence of extracellular factors on enzyme activity at the in vivo level.

The pattern of glycolytic enzymes and intermediates in newborn red cells differs from that observed in subjects with a red cell population of a similar mean age $(7,13,18)$. Metabolically, these cells appear to consume less glucose than would be predicted for red cells of such a young mean cell age (14). The relative deficiency of the regulatory enzyme, phosphofructokinase (PFK), that is characteristic of neonatal red cells, has been proposed as a possible cause of this metabolic handicap (13). It has also been suggested that there is a "fetal" PFK isozyme $(3,4,20)$ in cord blood, and this isozyme is more inhibited by adenosine triphosphate (ATP) (3) and may be less sensitive to $\mathrm{pH}$ activation (6) than the enzyme from adult red cells. Our laboratory has demonstrated that PFK has increased in vivo liability in cord blood (16), suggesting that the PFK deficiency in newborn red cells may be secondary to normal synthesis of an unstable enzyme. We have also recently reported (18) that PFK activity remains decreased at levels similar to those observed on days 1 and 4 of life until 8 to 9 wk of age when there is a significant increase in activity. This occurs at a time when the two most age-dependent enzymes, hexokinase (HK) and pyruvate kinase (PK), increase in activity which was felt to be consistent with resumption of active erythropoiesis by the infants' bone marrow. This interpretation is in agreement with the prior finding that "old" red cells in cord blood from term infants had a high fetal hemoglobin (3) and demonstrated to a marked degree those characteristics attributed to whole blood, namely decreased red cell PFK $(3,6)$ activity and increased activity of red cell phosphoglycerate kinase and enolase (6). These "older" red cells probably represent cells produced earlier in gestation, and it is likely that developmental changes observed in red cell enzymes during the first year of life represent the passage from fetal to "adult" erythropoiesis.

It would be expected that the pattern of glycolytic intermediates might yield the most useful information regarding metabolic events at the in vivo level and the possible significance of the decreased enzyme activity and altered kinetic properties of PFK because the concentration of glycolytic intermediates at any particular time may reflect enzymatic flux in vivo, according to the "crossover theorem" of Chance (1). However, the concentration of red cell glycolytic intermediates in neonates on day one of life has been reported in one study only (13), and reports describing developmental changes in glycolytic intermediates during the first year of life, except 2,3-diphosphoglycerate (2,3-DPG) (2), appear to be totally lacking in the literature. The pattern of glycolytic intermediates and ATP was thus evaluated in term infants from birth through the first year of life to detect differences other than those associated with a young red cell population.

\section{MATERIALS AND METHODS}

\section{SUBJECTS}

Blood from term infants, normal adults, and subjects with reticulocytosis was collected in tubes containing dried sodium heparin (Vacutainer; Becton-Dickinson and Co., Rutherford, NJ).

Term Infants. Blood was obtained on days 1 and 4; wk 3 to 4, 8 to 9,14 to 16 ; and months 5 to 6,8 to 9 , and 11 to 12 of life. Blood was obtained from the same infant on days 1 and 4 , and 
two subjects were followed sequentially from birth to 6 months of age. The remainder of the samples were obtained from random donors. Ten subjects were studied at each time interval.

Normal Adults and Subjects with Reticulocytosis. Blood from normal adults was obtained from laboratory personnel; samples from subjects with reticulocytosis were obtained from patients with hemolytic anemia who were attending hematology clinics. Blood from persons with known red cell enzyme deficiencies or an acute hemolytic episode was not used. Values cited for normal adults in this paper were obtained during the course of this study, not at a prior time.

PK activity was used as an index of red cell age in subjects with a young mean red cell population. PK is an "age-dependent" enzyme which implies that PK activity declines progressively as the red cell ages. Analysis of the rate of decline of this enzymatic activity can be performed by isolating discrete fractions of intact red cells of increasing density on a discontinuous density gradient (12). It has been demonstrated that layers of progressively increasing density reflect layers of increasing red cell age because "young" red cells are lighter and tend to migrate to the upper part of the gradient, and old red cells are heavier and concentrate at the bottom. There is predictable overlap of cells of varying densities (ages) in each layer because absolute separation of cells into homogeneous populations is not possible, hence the "mean cell age" of each fraction is correlated to its position in the gradient. This technique has permitted a quantitative estimation of the rate of decline of red cell enzymatic activity in vivo. The three most age-dependent glycolytic enzymes are HK, PK and aldolase with a $t^{1 / 2}$ of 33,29 , and 77 days, respectively (11). These three enzymes have been evaluated previously in term infants on the first day of life $(7,13,18)$ and have demonstrated increased enzyme activity that was comparable to that obtained from red cells from subjects with reticulocytosis. It has thus been concluded that the elevations in enzyme activities of HK, PK, and aldolase observed in red cells from term newborns are not unique characteristics, but merely reflect a red cell population with a young mean cell age. The two most age-dependent enzymes HK and PK would be expected to exhibit the greatest changes in enzyme activity with changes in the mean age of the red cell population. PK was chosen as an index of red cell age in these studies because PK from cord red cells had previously been demonstrated (16) to bear the same relationship between red cell age and density that had been demonstrated in red cells from adults, and cord and adult red cells have a similar rate of decline in activity in the discontinuous density gradient (16).

\section{ASSAY CONDITIONS}

Extracts for glycolytic intermediates and ATP were prepared at the bedside: $2 \mathrm{ml}$ of heparinized blood were immediately pipetted into $4 \mathrm{ml}$ of chilled $2 \mathrm{~N}$ perchloric acid, reextracted, and neutralized by methods previously described (13). 2,3-DPG was determined spectrophotometrically by the Schröter and Heyden (15) modification of the technique of Krimsky (8). ATP was analyzed spectrophotometrically (9) by means of yeast HK (BMC Corp.) and glucose-6-phosphate dehydrogenase (BMC Corp.). Fructose diphosphate, glyceraldehyde-3-phosphate, and dihydroxyacetone phosphate were determined simultaneously as described by Keitt (5) and are referred to as "total triose phosphates" ("TTP"). Glucose-6-phosphate (G-6-P), fructose-6-phosphate (F-6-P), 3phosphoglycerate (3-PG), 2-phosphoglycerate (2-PG), and phosphoenolpyruvate (PEP) were determined with modifications of the assay conditions described by Lowry et al. (10) and previously reported (19). G-6-P, F-6-P, TTP, 3-PG, 2-PG, and PEP were assayed fluorometrically with the use of an Eppendorf fluorometer (Brinkman Instruments) with a primary filter of $313 \pm 366 \mathrm{~nm}$ and a secondary filter of $400+3000 \mathrm{~nm}$. Pyruvate kinase activity was assayed as previously described (12). Data were analyzed statistically by the two-sample (unpaired) $t$ test and one-way analysis of variance.

\section{RESULTS}

\section{SUBJECTS WITH RETICULOCYTOSIS}

Using PK activity as an index of red cell age, subjects with reticulocytosis were divided into two groups: group I, with a range of PK activity from 333.9 to 479.3 units $/ 100 \mathrm{ml}$ red blood cells, representing a "moderately young" red cell population, and group II that ranged from 518.4 to 820.9 units $/ 100 \mathrm{ml}$ red blood cells, which represented a population with a younger mean cell age than group I. By dividing subjects in this manner, it was felt that more accurate "age-matched" comparisons could be made of glycolytic intermediates because the mean PK activity of group I was 392.7 \pm 51.2 units $/ 100 \mathrm{ml}$ red blood cells, a value comparable to that obtained in term infants on day 1 of life $(385.6 \pm 57.6)$. The mean red cell PK activity of group II was $665.4 \pm 112.6$ units $/ 100 \mathrm{ml}$ red blood cells. The concentration of glycolytic intermediates and ATP tended to be higher in groups I and II when compared to normal subjects, and the mean values obtained in group II were more elevated than in group I (Table I). Inasmuch as the levels of glycolytic intermediates tend to increase when there is a young mean red cell population, mean red cell PK activity was also determined at each time interval to evaluate the influence of red cell age on the pattern of glycolytic intermediates during the first year of life.

\section{G-6-P, F-6-P, AND TTP}

The concentration of red cell G-6-P was significantly increased on day 1 when compared to red cells from normal adults and group I $(P<0.001)$, continued to increase on day 4 and peaked at wk 3 to 4 of life at a mean concentration of $92.3 \mathrm{~m} \mu \mathrm{moles} / \mathrm{ml}$ red blood cells, which was 2.5 times greater than the level obtained in subjects with a red cell population of a similar mean age (group I). Mean G-6-P concentration decreased significantly between 3 and 4 and 8 and 9 wk of life $(P<0.001)$, and then continued to decline. At 1 year of age, the level of red cell G-6-P was compatible with the age of the red cell population. The changes in the concentration of red cell F-6-P tended to parallel those of G-6-P, but were of a lesser magnitude.

The concentration of TTP was significantly elevated for mean red cell age on day 1 of life $(P<0.01)$ peaked at day 4 at a level 1.9 times greater than the mean concentration observed in group I and then decreased significantly $(P<0.001)$ at wk 3 to 4 of age. The mean levels of TTP remained mildly elevated for red cell age for the entire first year of life, but this increase was not statistically significant by wk 8 to 9 of life $(P>0.1)$.

\section{2,3-DPG AND ATP}

The concentrations of red cell 2,3-DPG and ATP were normal for the age of the red cell population on day 1 of life. Between days 1 and 4 , there was a significant transient increase $(P<0.01)$ in the level of 2,3-DPG, and the 2,3-DPG concentration on day 4 was significantly elevated for the age of the red cell population $(P<0.01)$. Between day 4 and wk 3 to 4 of life, the level of 2,3DPG fell to values similar to those observed on day 1 of age and remained at this concentration until months 5 to 6 and 8 to 9 of life, when there was an increase in mean red cell 2,3-DPG concentration out of proportion to the age of the red cell population $(P<0.05)$. At 1 year of life, the levels of 2,3-DPG had declined to values compatible with mean red cell age.

Mean ATP similarly peaked transiently on day 4 and again at 5 to 6 months of age.

\section{3-PG AND 2-PG}

The mean red cell concentration of 3-PG and 2-PG were normal for red cell age on days 1 and 4 of life. The level of 3-PG remained relatively stable throughout the first year of life. The mean 2-PG concentration increased at 3 to 4 wk of age and remained elevated 


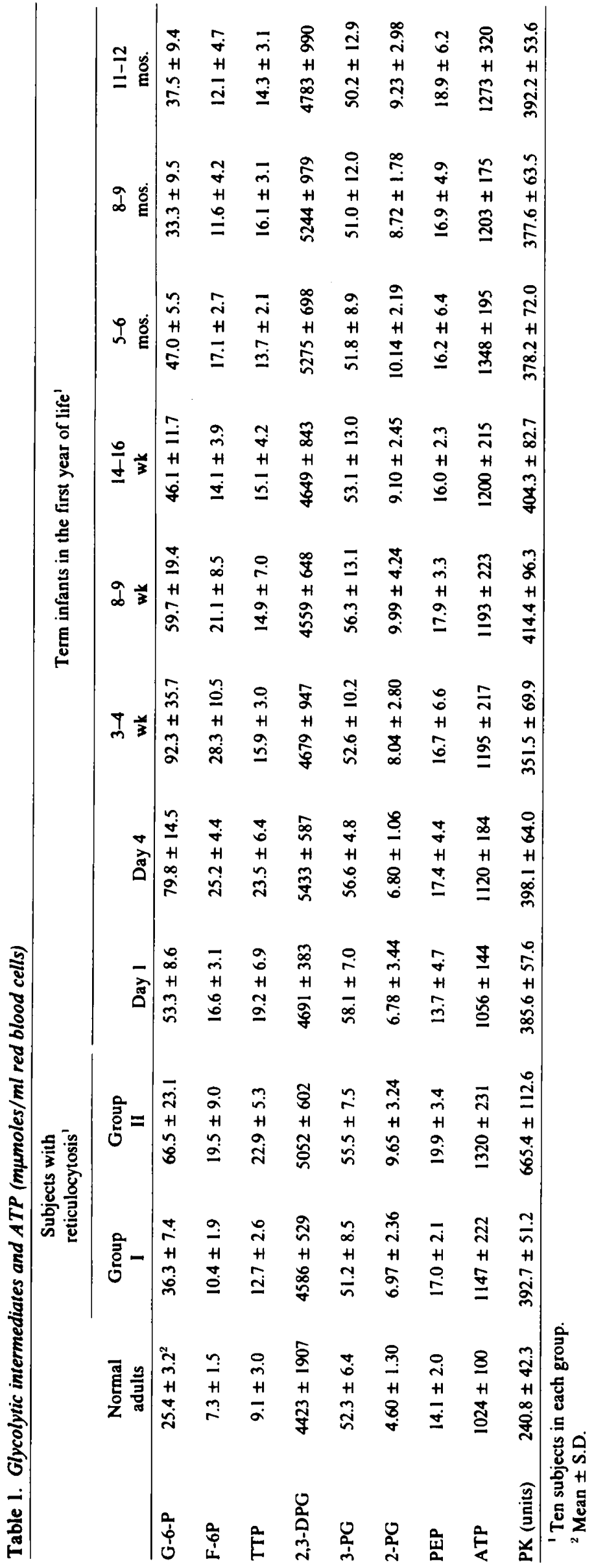

at 11 to 12 months of life, but this increase was not statistically significant $(P>0.05)$.

PEP

The mean concentration of red cell PEP was decreased for mean red cell age on day $\mathrm{I}$, but this decrease was not statistically significant $(P>0.05)$. PEP increased significantly betweeen days 1 and $4(P<0.05)$ to levels compatible with the age of the red cell population, and these values remained stable for the remainder of the first year of life.

\section{DISCUSSION}

Glycolytic intermediates in red cells from newborns have been investigated previously on day 1 of life (13). In that study, term and premature infants were contrasted with subjects with reticulocytosis. It was concluded that the levels of red cell G-6-P, F-6-P, dihydroxyacetone phosphate (triose phosphate), and 2,3-DPG were elevated in red cells from subjects with reticulocytosis. Premature and term infants had significantly decreased levels of 2,3DPG and PEP when compared to values obtained in red cells with a young mean cell age, but significant elevation of G-6-P, F6-P, and triose phosphate was found in premature infants only. It was proposed that the decrease in 2,3-DPG and PEP might be secondary to a relative block in glycolysis at the PFK step because significantly decreased activity of PFK on day 1 of life was also documented.

Our study has revealed significantly increased concentrations of G-6-P, F-6-P, and TTP in term infants on day 1 of life when compared to red cells of a similar mean age. PEP was decreased but not to a statistically significant degree. 2,3-DPG was normal when compared to red cells of a similar age. In the present study, subjects with reticulocytosis were divided into two groups, groups I and II, using the age-dependent enzyme PK as an index of red cell age. PK was chosen because the activity of this enzyme is appropriately elevated for mean cell age in the newborn period when compared to red cells from subjects with reticulocytosis $(6$, 13, 17). In this manner, it was felt that more age-matched results could be obtained because the mean PK activity of group I was similar to that obtained on days $I$ and 4 of life in term infants. The glycolytic intermediates in general were higher in group II than in group I. The significant elevation of G-6-P, F-6-P, and TTP in term infants and lack of a significant decrease in PEP and 2,3-DPG in our study when compared to the one cited above (13) are probably secondary to more closely age-matched comparisons in the present investigation.

The mean concentration of PEP increased by day 4 of life and remained relatively stable for the remainder of the first year of life. 2,3-DPG increased significantly between days 1 and 4 and then decreased by 3 to $4 \mathrm{wk}$ to levels similar to those observed on day 1 , which is similar to results previously reported (2). At one year of age, the levels of glycolytic intermediates were similar to those observed in group I as was mean PK activity which is consistent with the persistence of a relatively young red cell population.

Analysis of the most significant sequential changes in red cell glycolytic intermediates revealed that the concentration of G-6-P was elevated on days 1 and 4 of life when compared to red cells of a similar mean age (group I). These levels continued to increase and peaked at 3 to 4 wk of life at a mean concentration that was 2.5 times greater than the value observed in "group I." This increase appeared to be independent of red cell age because mean PK activity did not increase between day 1 and wk 3 to 4 of life (18), and a significant decrease in the concentration of G-6-P occurred between wk 3 and 4 and 8 and 9 at a time when mean PK activity increased (18). The levels of red cell TTP were also increased and peaked on day 4 of life at a concentration 1.9 times that observed in group I and then decreased significantly by wk 3 to 4 of life. Thus, the increase in TTP was transient and had decreased significantly by 3 to $4 \mathrm{wk}$ of age, at a time when the 
mean G-6-P concentration reached its highest level. This pattern of glycolytic intermediates is highly suggestive of a relative block in glycolysis at the PFK step, and this "metabolic handicap" persists beyond the immediate neonatal period.

We have previously demonstrated that mean PFK activity does not increase significantly until wk 8 to 9 of life (18) and remains relatively unchanged from day 1 through wk 3 to 4 . During this same period HK activity decreases (18), resulting in a decreasing $\mathrm{HK} / \mathrm{PFK}$ ratio. Despite the decrease in the HK/PFK ratio and stable PFK activity, the pattern of glycolytic intermediates reveals an increasing concentration of G-6-P that peaks at wk 3 to 4 coupled with a significant decrease in TTP between day 4 and wk 3 to 4.

These data suggest that the relative block in glycolysis at the PFK step and resulting pattern of glycolytic intermediates in term infants are not solely due to decreased PFK levels. It is likely that altered kinetic properties of PFK and/or modulation of enzyme activity by extracellular factors may also play a significant role at the in vivo level. Intracellular $\mathrm{pH}$ has been evaluated and was normal (17). Thus, the suggestion that a fetal PFK isozyme exists $(3,4,20)$ which is more inhibited by ATP (3) and may be less sensitive to $\mathrm{pH}$ activation (6), may have functional significance at the in vivo level.

\section{REFERENCES AND NOTES}

1. Chance, B., Holmes, W., and Higgins, J:: Localization of interaction sites in multicomponent transfer systems: Theorems derived from analogues. Nature (Lond.), 182: 1190 (1958).

2. Delivoria-Papadopoulos, M., Roncevic, N. P., and Oski, F. A.: Postnatal changes in oxygen transport of term, premature, and sick infants: the role of red cell 2.3-diphosphoglycerate and adult hemoglobin. Pediatr. Res., 5: 235 (1971).

3. Kahn, A., Boyer, C., Cottreau, D., Marie, J., and Boivin, P.: Immunologic study of the age-related loss of activity of six enzymes in the red cells from newborn infants and adults-evidence for a fetal type of erythrocyte phosphofructokinase. Pediatr. Res., 11: 271 (1977).

4. Kahn, A., Cottreau, D., Boyer, C.. Marie, J., Galand, C., and Boivin. P.: Causal mechanisms of multiple acquired red cell enzyme defects in a patient with acquired dyserythropoiesis. Blood, 48: 653 (1976).

5. Keitt, A. S.: Hemolytic anemia with impaired hexokinase activity. J. Clin. Invest., 48: 1997 (1969).

6. Komazawa. M., and Oski. F. A.: Biochemical characteristics of "young" and "old" erythrocytes of the newborn infant. J. Pediatr., 87: 102 (1975).

7. Konrad. P. N., Valentine. W. N., and Paglia, D. E.: Enzymatic activities and

Copyright ( 1981 International Pediatric Research Foundation, Inc. 0031-3998/81/1501-0034\$02.00/0 glutathione content of erythrocytes in the newborn: comparison with red cells of older normal subjects and those with comparable reticulocytosis. Acta Haematol., 48: 193 (1972).

8. Krimsky, I.: D-2,3-diphosphoglycerate. In: H. U. Burgmeyer: Methods of Enzymatic Analysis. Ed. I, p. 238-240 (Academic Press, Inc., New York, 1963).

9. Lamprecht. W.. and Trautschold. I.: Adenosine-5'-triphosphate. Determination with hexokinase and glucose-6-phosphate dehydrogenase. In: H. U. Burgmeyer: Methods of Enzymatic Analysis. Ed. 1, p. 543-55I (Academic Press Inc., New York, 1963).

10. Lowry, O. H., Passonneau, J. V., Hasselberger, F. X., and Schultz, D. W.: Effect of ischemia on known substrates and cofactors of the glycolytic pathway in brain. J. Biol. Chem., 239: 18 (1964).

11. Piomelli, S., and Corash, L.: Hereditary hemolytic anemia due to enzyme defects of glycolysis. In: H. Harris, K. Hirschhorn: Advances in Human Genetics. Vol 6. p. 165-240 (Plenum Press, New York, 1976).

12. Piomelli, S., Corash, L. M., Davenpor, D. D., Miraglia, J., and Amorosi, E. L.: In vivo lability of glucose-6-phosphate dehydrogenase in $\mathrm{Gd}^{\wedge}-$ and $\mathrm{Gd}$. Medieeranean deficiency. J. Clin. Invest., 47: 940 (1968).

13. Oski, F. A.: Red cell metabolism in the newborn infant. V. Glycolytic intermediates and glycolytic enzymes. Pediatrics, 44: 84 (1969).

14. Oski, F. A., and Smith, C.: Red cell metabolism in the premature infant. III Apparent inappropirate glucose consumption for cell age. Pediatrics, 4I: 473 (1968).

15. Schröter, W., and Heyden. H.: Kinetik des 2,3-Diphosphoglyceratumsatzes in menschlichen Erythrocyten. Biochem. Z., 341: 387 (1965).

16. Travis, S. F., and Garvin, J. H., Jr.: In vivo lability of red cell phosphofructokinase (PFK) in term infants: the possible molecular basis of the relative PFK deficiency in neonatal red cells. Pediatr. Res., 11: 1159 (1977).

17. Travis, S. F., Kumar, S. P., and Delivoria-Papadopoulos, M.: Red cell metabolic alterations in postnatal life in term infants: possible control mechanisms. Pediatr. Res. (in press).

18. Travis, S. F., Kumar, S. P., Paez, P. C., and Delivoria-Papadopoulos, M.: Red cell metabolic alterations in postnatal life in term infants: glycolytic enzymes and glucose-6-phosphate dehydrogenase. Pediatr. Res., 14: 1349 (1980).

19. Travis, S. F., Morrison, A. D., Clements, R. S., Jr., Winegrad, A. I., and Oski, F. A.: Metabolic alterations in the human erythrocyte produced by increases in glucose concentration. The role of the polyol pathway. J. Clin. Invest., 50: 2104 (1971).

20. Vora, S. and Piomelli, S.: Fetal isozyme of phosphofructokinase of newborn erythrocytes Pediatr. Res. (Abstract), 11: 483 (1977).

21. The authors would like to express their appreciation to Patricia Gillmer and Patricia O'Neal for their technical assistance and Geri Weinberg for her secretarial help in the preparation of this manuscript.

22. Requests for reprints should be addressed to: Susan F. Travis, M.D., Thomas Jefferson University School of Medicine, Cardeza Foundation for Hematologic Research, 1015 Walnut Street, Philadelphia. PA 19107 (USA).

23. This research was supported in part by NIH grant R01-HD-10213.

24. Received for publication January $7,1980$.

25. Accepted for publication May 23, 1980. 